\title{
Validation of Novel Transcriptional Targets that Underpin CD44-promoted breast cancer cell invasion
}

Salma. M.S. Ahmad, Hanan Nazar, Nouralhuda Emad Alatieh, Maryam AL-Mansoob, Zainab Farooq, Muna Yusuf, Allal Ouhtit ${ }^{\star}$

$$
\text { ABSTRACT }
$$

ABSTRACT

Introduction

most common cancer worldwide, and metastasis is its worst aspect and the first cause of death. Metastasis is a multistep process, where an thasion is a recurring event. The process of $B C$ cell nvasion involves three major factors, including cell adhesion molecules (CAM), proteinases and Growth actors.CD44, a family of CAM proteins and the hyaluronic (HA) cell surface receptor, acts as cell differentiation cell migration/invasion and apoptosis regulator.

Rationale:

We have previously established a tetracycline (Tet)-OFFregulated expression system, both in vitro and in vivo (Hill et al, 2006). As a complementary approach, the highly metastatic MDA-MB-231 BC cells expressing high levels of endogenous CD44s (the standard form of CD44), was Cultured in the presence and absence of $50 \mathrm{\mu g} / \mathrm{ml}$ of $\mathrm{HA}$, RNA samples were isolated from both cell experimental models, and microarray analysis (12K CHIP from Affymetrix) was applied. More than 200 CD44s transcriptional target genes were identified and were sub-divided into groups of genes based on their function cell motility, cytoskeletal organization, ability to degrade ECM, and cell survival.

Hypothesis:

Among these 200 identified genes, we selected seven genes (ICAP-1, KYNU, AHR, SIRT1, SRSF8, PRAD1, and $S O D 2$ ) and hypothesized that based on evidence from literature, these genes are potential novel targets $c$ CD44-downstream signaling mediating BC cell invasion.

\section{$\underline{\text { Specific Aims }}$}

\section{Pursuant $t$}

1- Structural validation of ICAP-1, KYNU, AHR, SIRT1 $S R S F 8, P R A D 1$ and SOD2 as novel transcriptional targets of CD44/HA-downstream signaling at both RNA and Protein level using rever chain reaction (RT-PCR) and Western Blot respectively. 2-Functional validation of ICAP-1, KYNU, AHR, SIRT1,
SRSF8, PRAD1and SOD2 as novel transcriptional targets that underpin CD44-promoted $B C$ cell migration usin wound healing assay after the transfection with siRNA.

\section{LITERATURE REVIEW \\ Studies stated that CD44 increased BC metastasis into various organs, including , for instance: liver, expression of $C D 445$ was suppressed in malignant $B$ tissues compared to benign breast tissues (McFarlane et al.,2015) \\ Other studies showed that changing from vCD44 t sCD44 isoforms enhanced the formation of epithelial mesenchymal transition (EMT). The re-expression CD44 activated the inhibited EMT phenotype in th CD44-knockdown cells, with decreased expression o epithelial markers and increased expression o mesenchymal markers (Chen, Zhao, Karnad, \& Freemar 2018). In contrast, studies showed that expression he different CD44 variant isoforms, CD44V3, CD44v CD44v6, and CD44v7-8 promoted BC metastasis produced large tumors, and lowered survival rate (Rize et al., 2018), (Mayer et al., 2008}

\section{Structure of CD44}

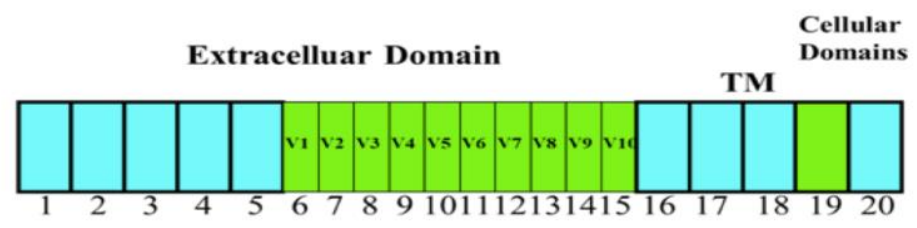

Short Tail
Long Tail
METHODOLOGY

HA

Cell Culture

of RNA

samples

\section{- 10 l RNAto CDNA: High Capacity} CDNA Reverse Transcriptionkit.

- RTPCR Optimization:2 $\mu$ lof 50

$\mathrm{ng} / \mathrm{\mu l}$ control cDNA were amplified using $14.5 \mu$ l of (AmpliTaq Gold 360 Master Mix kit), $49^{\circ} \mathrm{C}, 51^{\circ} \mathrm{C}, 5^{\circ} \mathrm{C}$,

RTPCR $577^{\circ} \mathrm{C}$ and 59

- RTPCR Process: 95ㄷ for 10 minutes. 40 cycles $95^{\circ} \mathrm{C}$ for 30 seconds, Tmat $50^{\circ} \mathrm{C}$ to $58^{\circ} \mathrm{C}$ ) for 1 minute each, extension step at $72^{\circ} \mathrm{C}$ for 1 minute final extension $72^{\circ} \mathrm{C}$ for 10 minutes.

\section{- CD44 and GAPDH PCR products} were run in a $1.5 \%$ agarose gel with $3 \mu \mathrm{l}$ of SYPR green stain. The gel then was set at $120 \mathrm{~V}$ for 45

Analysis of electrophoretic bands

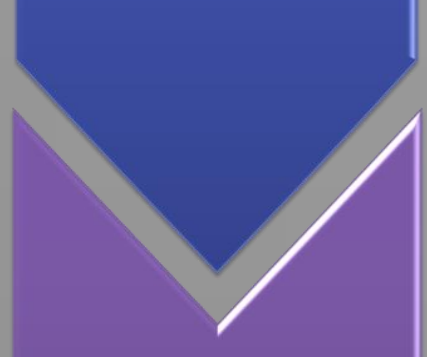

Statistical Analysis

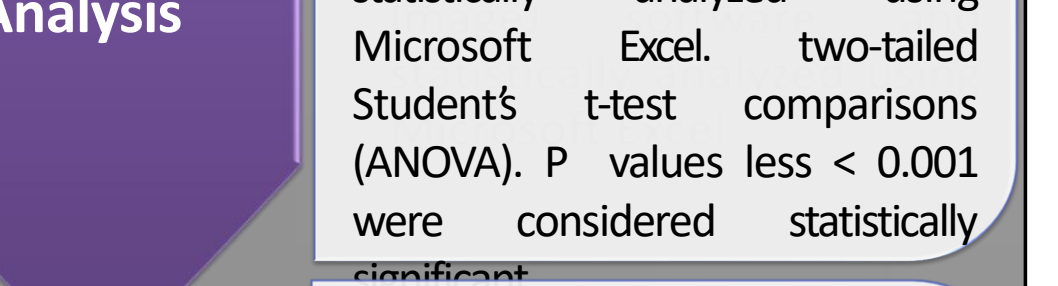

Transportation of proteins to nitrocellulose membrane by electrophoresis.

- Block for 1 hr. with 5\% non-fat milk minutes.

ICAP-1A PCR product was run in a $1.5 \%$ agarose gel, while KYNU was run in a $2 \%$ gel that contains gel then was set at $70 \mathrm{~V}$ for 30 minutes

Observed bands on the gel for each gene at 24hrs post-HA treatment were quantified using the Imagel software and statistically analyzed using Microsoft Excel two-tailed Student's t-test comparisons (ANOVA). $\mathrm{P}$ values less $<0.001$ - Probing with primary antibodies first overnight.

- secondary antibody for $1 \mathrm{hr}$. - Special reagent was added to enable visualization - CGS device was used for detecting.

- control group, the cells were cultured in complete DMEM medium that contains $1 \%$ L-Glu, $1 \%$ peni./strep., and $10 \%$ (FBS). - MDA-231 BC cell line

SiRNA Cell Culture cultured in complete DMEM medium that contained lipofectamine reagent for 72 hrs.

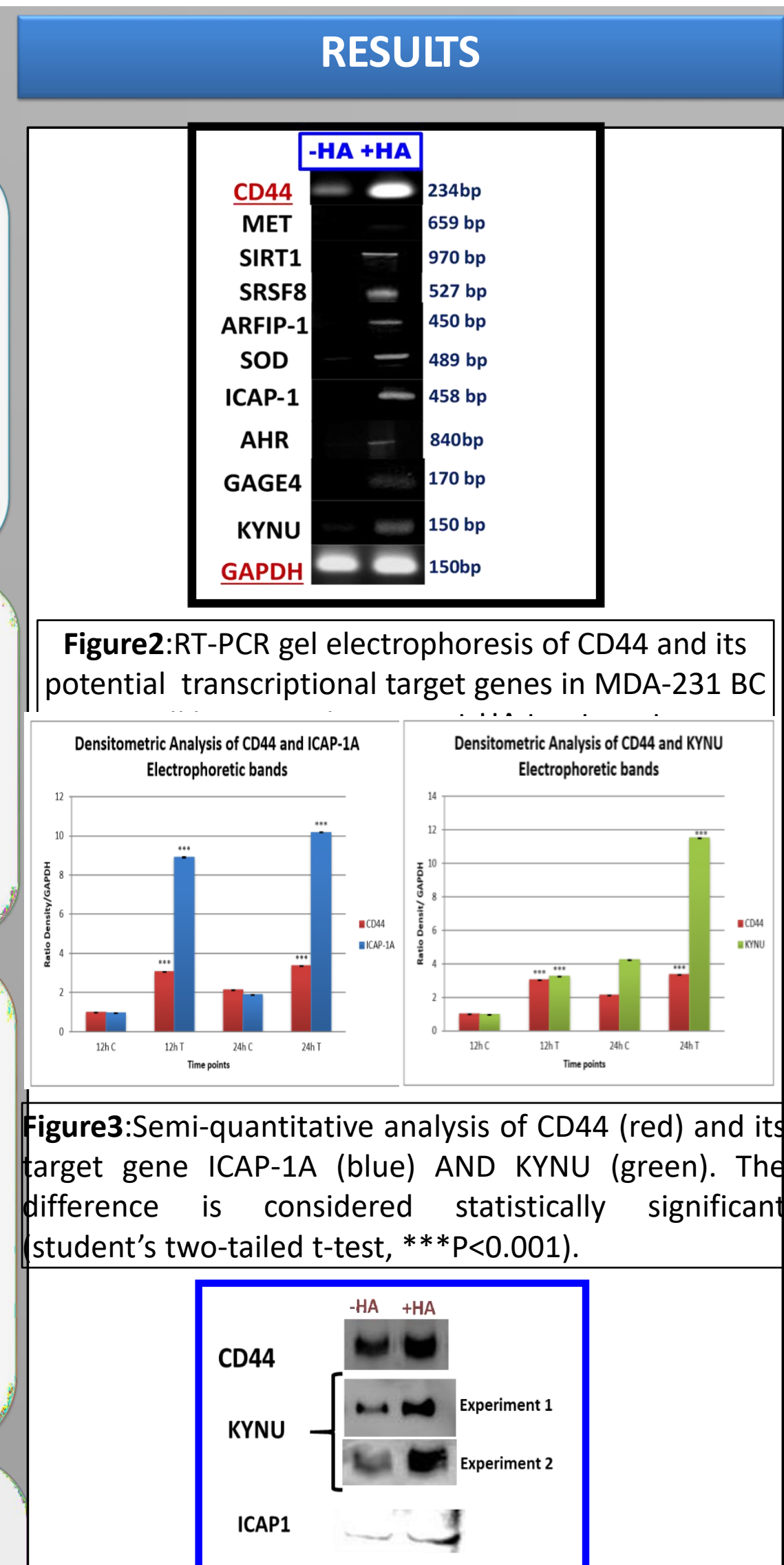

Figure4: Western blot results showing 2 major transcriptional targets of CD44 in MDA-231 BC cell line at $24 \mathrm{~h}$ post treatment.

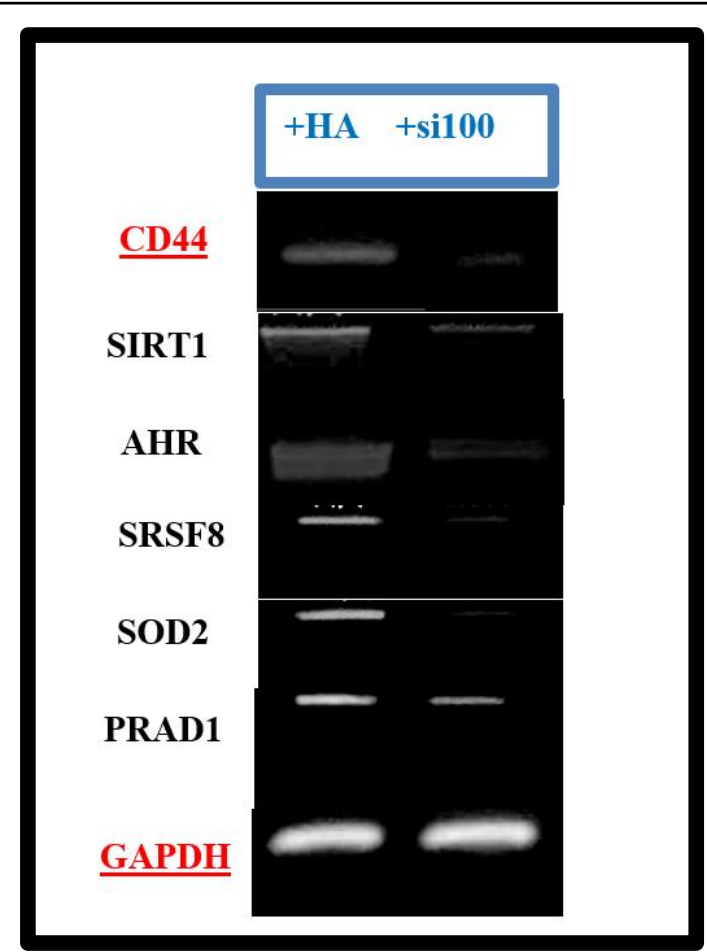

Figure5: RT-PCR gel electrophoresis of CD44 and its potential transcriptional target genes in MDA 231 BC cell line at 72 hours postsiRNA.treatment.

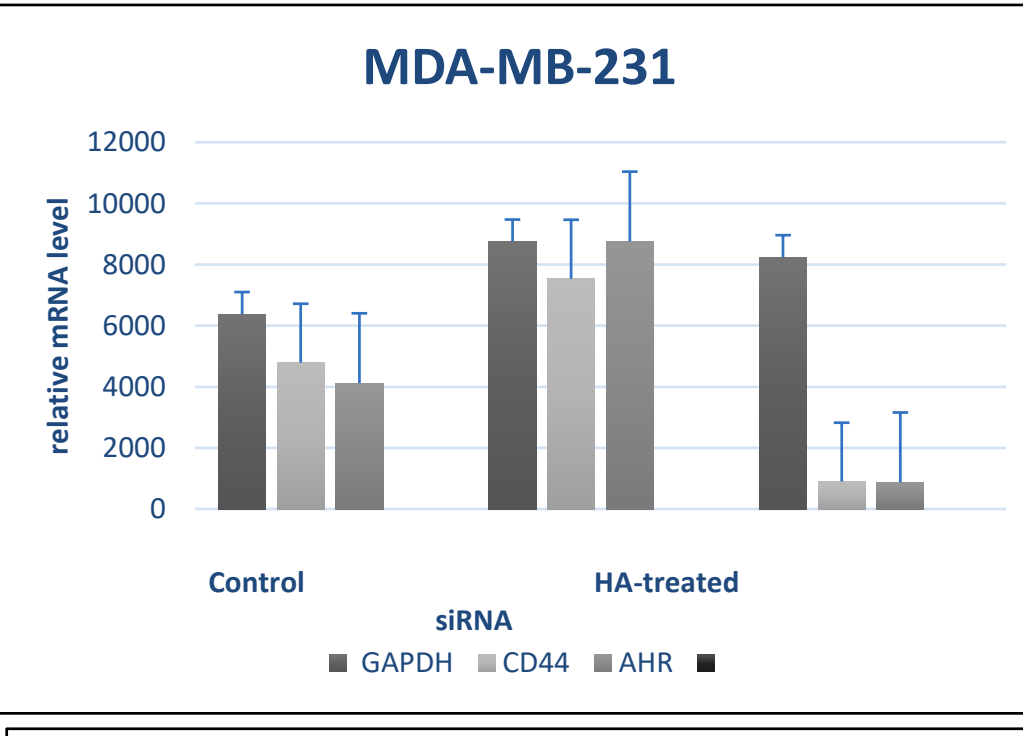

Figure6: Semi-quantitative analysis of CD44 statistically significant (student's two-tailed t-test, $* * * P<0.001)$.
DISCUSSION

According to our results the specified transcriptional targets of $\mathrm{CD} 44 / \mathrm{HA}$ are proven structurally by using $\mathrm{RT}$ PCR and Western Bot. Literature review also supports our hypothesis as ICAP-1 activate KRIT1 leading to the activation of NOTCH signalling which in return will ctivate PI3K/AKT pathway resulting in tumor progression and survival (Stroeken et al., 2006). Similarly KYNU, AHR and SIRT1 interfere in the IIKK/AKT pathway leading to tumor proliferation and metastasis (Ci et al., 2019)(Ye et al., 2018) (Jin, X., Wei, ., et.al. 2018)

According to (Liu Z, He Q, et.al 2015) SOD2 has the capability to promote both migration and invasion v its interaction with C-MYC protein. Furthermore PRAD1 which is also known as CCND1 was found to nteract with MAPK pathway transforming human embryonic lung fibroblast into malignant tumor.

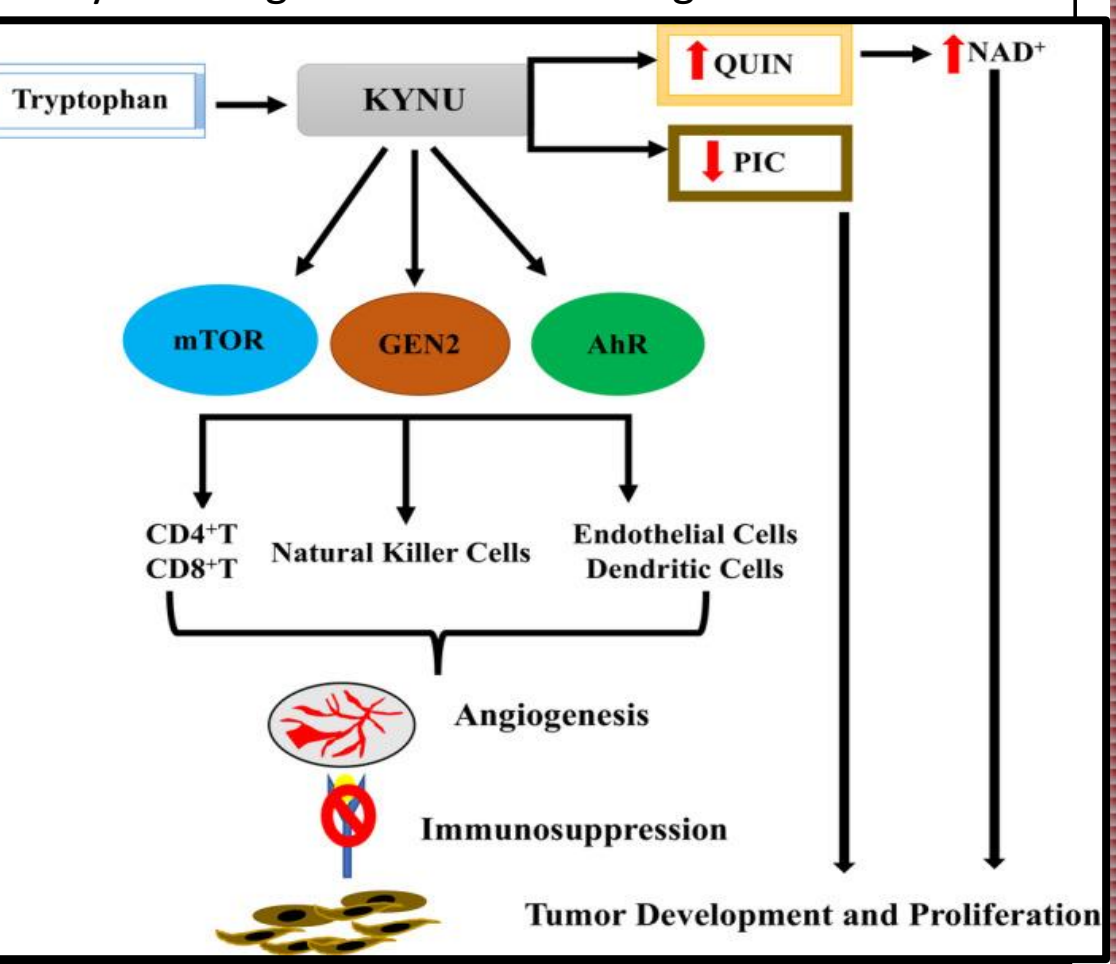

Figure7: KYNU pathways associated with tumor development (Al-Mansoob, M., Ouhtit, A. 2021)

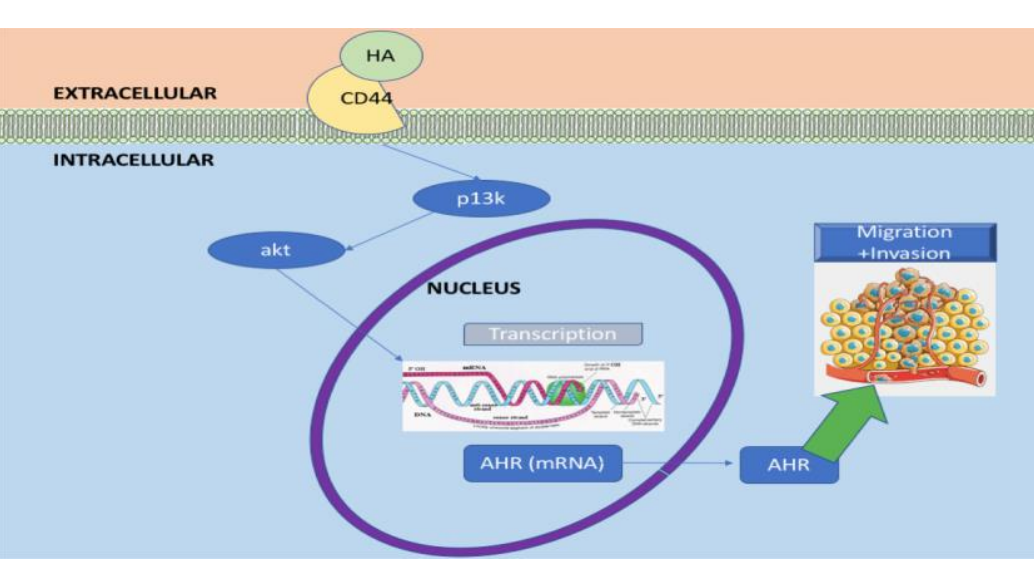

Figure8: AHR mechanisms that promote CONCLUSION

In conclusion, using semi-quantitative RT-PCR, western blot and siRNA transfection analysis, our study confirmed that the specified targets are

Unfortunately, because of several restrictions, due to COVID pandemic, a number of experiments were not completed.

further validate these genes, additional in vitro experiments using RT-PCR and western blot analyse on samples isolated from BC cells treated with CD44 siRNA scenario are required. Additional experiments using various other $\mathrm{BC}$ cells lines, including normal epithelial breast cells are also needed to validate our results.

\section{REFERENCES}

Hill A, Mcfarlane, S, Mulligan, $K$, Gillespie, $H$, Draffin, $\downarrow$ E. E, Timble A. Waugh, D. J. J. (2006). Cortactin underpins CD44-promoted invasion and adhesion of breast cancer cells to bone marrow endothelial cells. Oncogene, 25(45), 6079-6091. do 10.1038/sj.onc.1209628

Al-Mansoob, M., Gupta, I., Stefan Rusyniak, R., \& Ouhtit, A. (2021). KYNU, a novel potential target that underpins CD44-promoted breast tumour cell invasion. Journal of cellular and molecular medicine,
https://doi.org/10.1111/jcmm.16296 